\title{
U.S. Geological Survey Mentoring Program- Paired for a Powerful Science Future
}

"To be able to perform well in an organization, it is very important to understand the organization and to know what's expected of you. That information does not always come easily. There are employee handbooks, policy documents, and so forth, but they don't tell the whole story. Having someone experienced in the ways and culture of the organization to talk to, who can guide you, is invaluable. In addition, organizations need to be able to transfer knowledge from experienced workers to new employees. Planning for succession helps ensure continuity and lessens the loss of critical skills and knowledge. The USGS Mentoring Program plays a valuable role in accomplishing these desired outcomes."

—Mark Myers, Director, U.S. Geological Survey

7 he U.S. Geological Survey (USGS) prides itself in its excellence in 1 science. The resource bank of skills and knowledge that is contained within the current employees of the USGS is what makes our science excellent. With an aging workforce, we must ensure that the knowledge and skills represented by those years of experience are passed to new employees. To ensure that this bank of knowledge and experience is not lost and thereby sustain the excellence of our science, the Mentoring Program focuses on intentional mentoring, the deliberate transfer of skills and knowledge. Skills transfer from more experienced employees to those who are less experienced is critical. By placing an emphasis on intentional mentoring, we help to meet the scientific and technical needs of the employees by offering a cost-effective way to gain knowledge and skills necessary to maintain excellence in science. By encouraging and fostering a mentoring atmosphere within the USGS, we are investing in the future of our organization. With improved technical skills, increased job effectiveness, and resulting satisfaction, USGS employ-
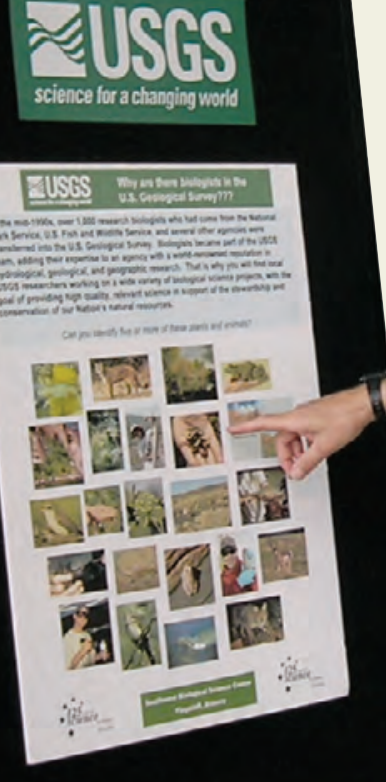
science for a changing world ees will not only be more invested and engaged, they will also be able to work smarter, thus benefiting from the experience of their mentor.

\section{What is Mentoring in the USGS?}

Mentoring is a tool that provides cost-effective training and development. It also encourages professional and personal growth. Mentoring in the USGS is a developmental partnership in which two people invest time, know-how and effort to enhance growth, knowledge, and skills and to accelerate acculturation and engagement. This partnership transcends duty and obligation and often involves coaching, networking, sponsoring, and career counseling. It is an incredibly effective form of training with a
"Participating in the USGS Mentoring Program has been one of the highlights of my first year of employment with the USGS. I had set out as my goal to learn more about how USGS and DOI in general worked. What I got from my mentoring experiences was much more than that." - USGS Mentoree that provides unique benefits to both mentoring partners.

Check out the online course "Introduction to Mentoring" at URL http://oedbreeze.cr.usgs.gov/mentoringintro/ to discover what the program is about and how it can help you.

\section{Vision and Goals}

The vision of the USGS Mentoring Program is to build and sustain a culture that fosters meaningful partnerships and connections among interested employees to increase skills, knowledge, satisfaction, and engagement.

The USGS Mentoring Program is designed to help achieve the following goals in service to science:

- Facilitate interdisciplinary collaboration and support of integrated science activities

- Transfer knowledge, skills, and abilities

- Accelerate acculturation and increase employee engagement and productivity for new employees

- Improve recruitment and retention

- Promote development of leadership skills at all levels

- Support personal and professional development 


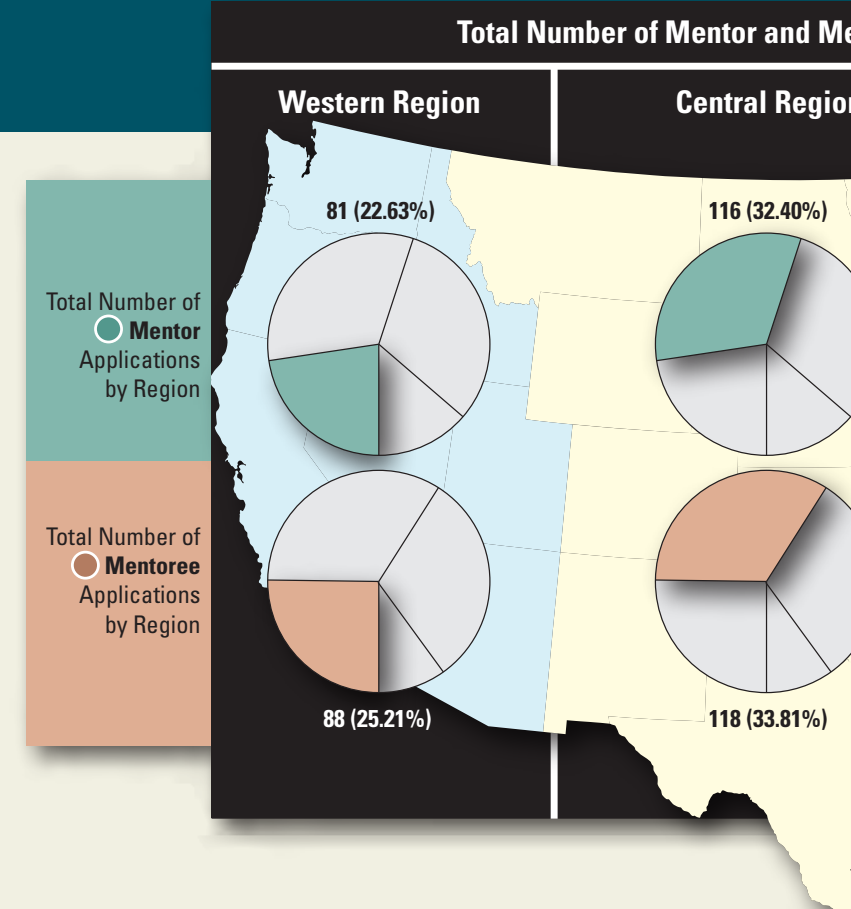

The intent of the USGS Mentoring Program is to make mentoring easily accessible and accepted as a cost-effective tool for growth and development of all of its employees. Our purpose is to build on the natural mentoring foundatio
already in place and create an intentional and deliberate already in place and create an intentional and deliberate mentoring culture in the USGS. To create his culture, the USGS mist bing mentoring to the forefront of every employee's mind as a conscious choice for training and development. tool to effectively and efficiently equip newer employees with necessary skills and a greater sense of belonging to the organization. This ensures the USGS maintains its knowledge bank, which helps to maintain its status as a premier science agency. It also accelerates productivity and increases engagement.

\section{Benefits of the USGS Mentoring Program}

The USGS Mentoring Program allows leaders to become great leaders through experiskills by developing them early giving them a quality example to follow and offering the the opportunity to lead in a safe and constructive environment. In the USGS Mentoring Program classes are specifically designed to teach and hone leadership skills for all participants. The mentoring partnerships are structured to build trust and allow participants the opportanity to learn and pracice new skils. The USGS Mentong Progrant allows participants to grow and fosters informed risk-taking so that participants (mentor and mentoree) can leadership as well. Participants leave this program prepared for the opportunity to lead well, manage wisely, and keep the USGS on the forefront of excellent science.

The Mentoring Program is a valuable tool that can be used by employees to learn about the organization, their jobs, and themselves. It also encourages employees to move throug and adapt to change. Partnerships are created by placing the more experienced with the less experienced, thereby giving the less experienced an example to follow. It also provides person to give them a broader perspective of the USGS. The more experienced persol meets regularly with a mentoree and helps renew their focus, their energy, and thers sense purpose, offering a fresh pair of eyes through which to view the changes in the USGS (RIGHT) Mentor Alan Ward, with the Office of Organizational and Employee Developmen in Denver, is shown with Traci Hoff, a mentoree from the Idaho Water Science Center. Traci is a new USGS employee, who is interested in techinical editing. She was flown to competency job-related tasks, tools of the trade, and other aspects of work are exchanged

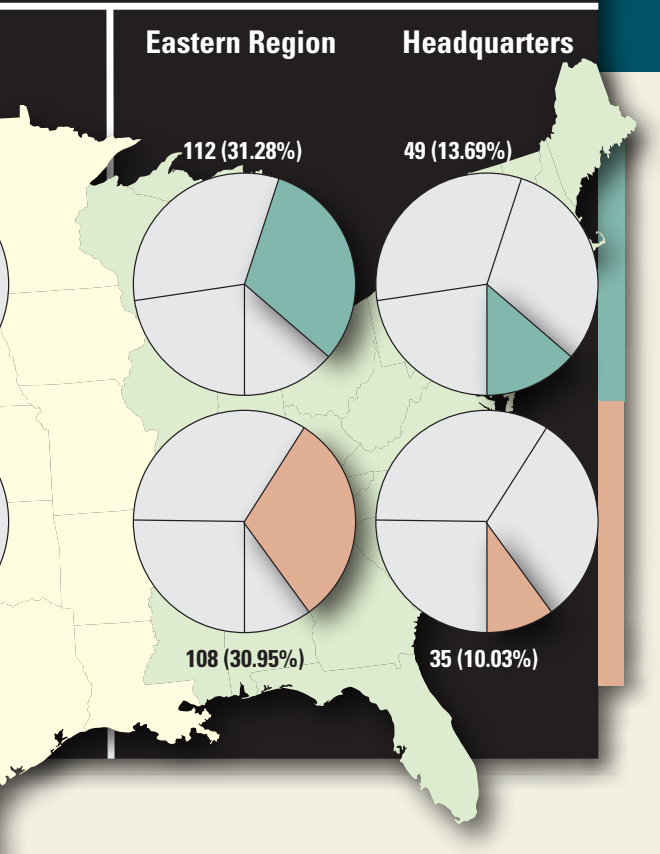

"So far, I'm the winner in this relationship. Seems that despite the chaos of the multiple reorganizations I ' $m$ having to work through, I have a critical mission to see through to completion and that's providing a different focus to my work life, and it's becoming a positive force in all tiso these days. I think if the organization wants to revitalize a tired "

Benefits of Mentoring Partnerships between the Mentor and the Mentoree

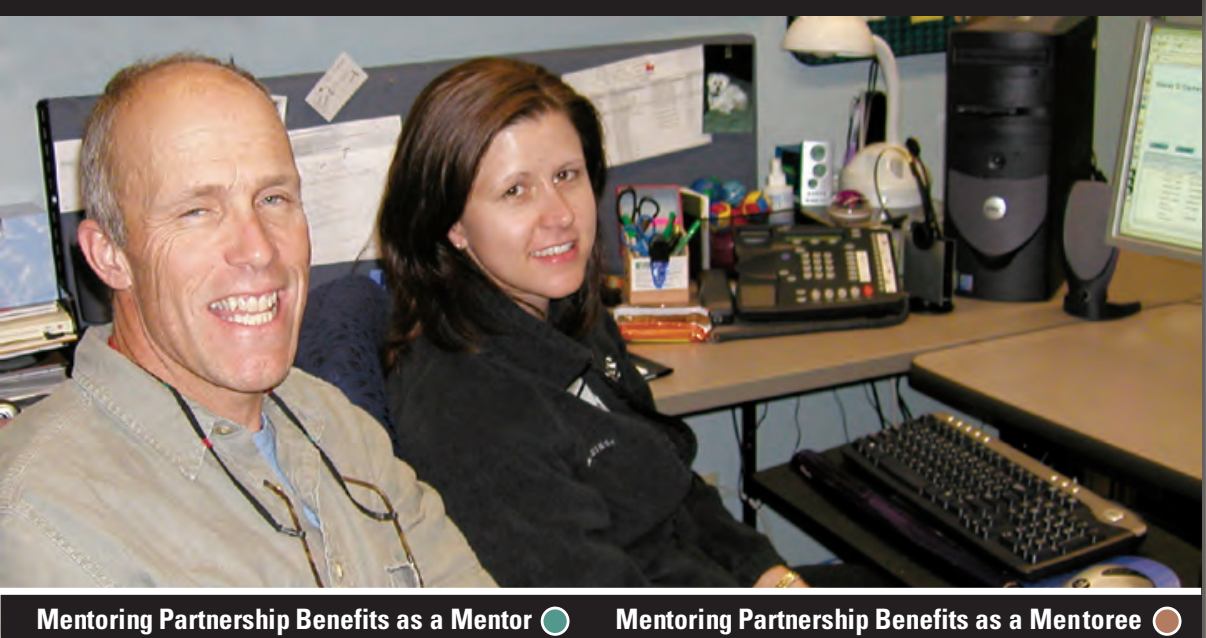

Supports developmental needs of employees Obtains a trusted counselor Finds inspiration and fresh ideas Improves job effectiveness Helps shape the evolving USGS Grows Leadership skills Establishes new relationships Increases network of contacts Helps to grow networks Obtains career guidance Shares knowledge and talents Enhances Professional development

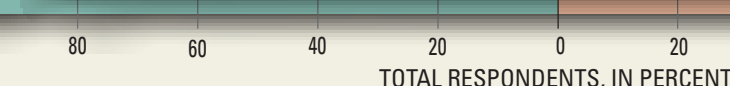

The USGS Mentoring Program The USGS Mentoring Program is primarily composed of two components: One-Year Guided and Self-
Directed. These two components offer flexibility and participation to the degree that time and interest allow.

The One-Year Guided Formal Mentoring Program

The One-Year Guided Formal Mentoring Program is a structured approach to mentoring intended to guide the pairs through their one-year partnerships. The One-Year Guided Program offers employees two opportunities, termed "rollouts," per fiscal year to participate, one in the fall and one in the spring. The program is open to Program participate in a two-day shadowing event, formal mentoring training, and have opportunities to attend monthly mentoring exchanges. Mentoring exchanges are one-hour cyber seminars on topics pertinent to menoring or to the USGS in general. Employees with five years or less of USGS service are invited to apply for a mentor, and all other USGS employees are invited to apply to be a mentor. Wherever possible, partnerships will be paired within the same region/headquarters. Supervisory approval is required for all participants. Applications are accepted online at URL hitp://geology.usgs.gov/usgs/mentoring.htm

- The requirements of participants in the One-Year Guided Formal Mentoring Program are as follow s:

- Attendance of a Cyber Partnership Training seminar in conjunction with a two-day Shadowing Event

Involvement in mentoring activities for 2 to 4 hours a month

Attendance at three cyber mentoring exchanges anytime during the one-year partnership

Agreement to participate in the Mentoring Program for one year

Participation in three brief surveys throughout the one-year partnership

Establishment of a Mentoring Agreement and an Action Plan

Participation at the end of the year in a Mentoring Program Partnership celebration and wrap-up session

"The Mentoring Program has been a wonderful experience for me. My Mentor has been a great listener and adviser to me." - O USGS Mentoree

"There was no downside for me in the mentoring experience. Through this relationship I was able to fasttrack getting to know the USGS." — O USGS Mentoree

"Mentoring is a mutual benefit in that I feel I have gained just as much as I have given. I truly feel that the mentor-mentoree relationships in which I have been involved have helped me to do my job better as a - o USGS Senior Level Scientist, Mentor 


\section{Self-Directed Mentoring}

The Self-Directed component of the USGS Mentoring Program is a less-structured approach to mentoring. The Self-Directed component is open to all USGS employees at any time who have the necessary supervisory approval. The partnership is managed and maintained solely by the participants. Participation begins by attending a three-hour cyber seminar in which participants can learn how to start a mentoring partnership. These cyber seminars provide training that supports mentorees in finding a mentor, focus on mentoring skills, and provide techniques for developing successful mentoring partnerships. A schedule for the dates and times of cyber seminars can be found online at http://training.usgs. gov and clicking on "Mentoring Program" and then choosing "Upcoming Events." Participants in the Self-Directed Program are asked to complete an online form, registering their contact information into the Mentoring database. They will also be asked to complete an Action Plan and be given access to USGS mentoring resources.

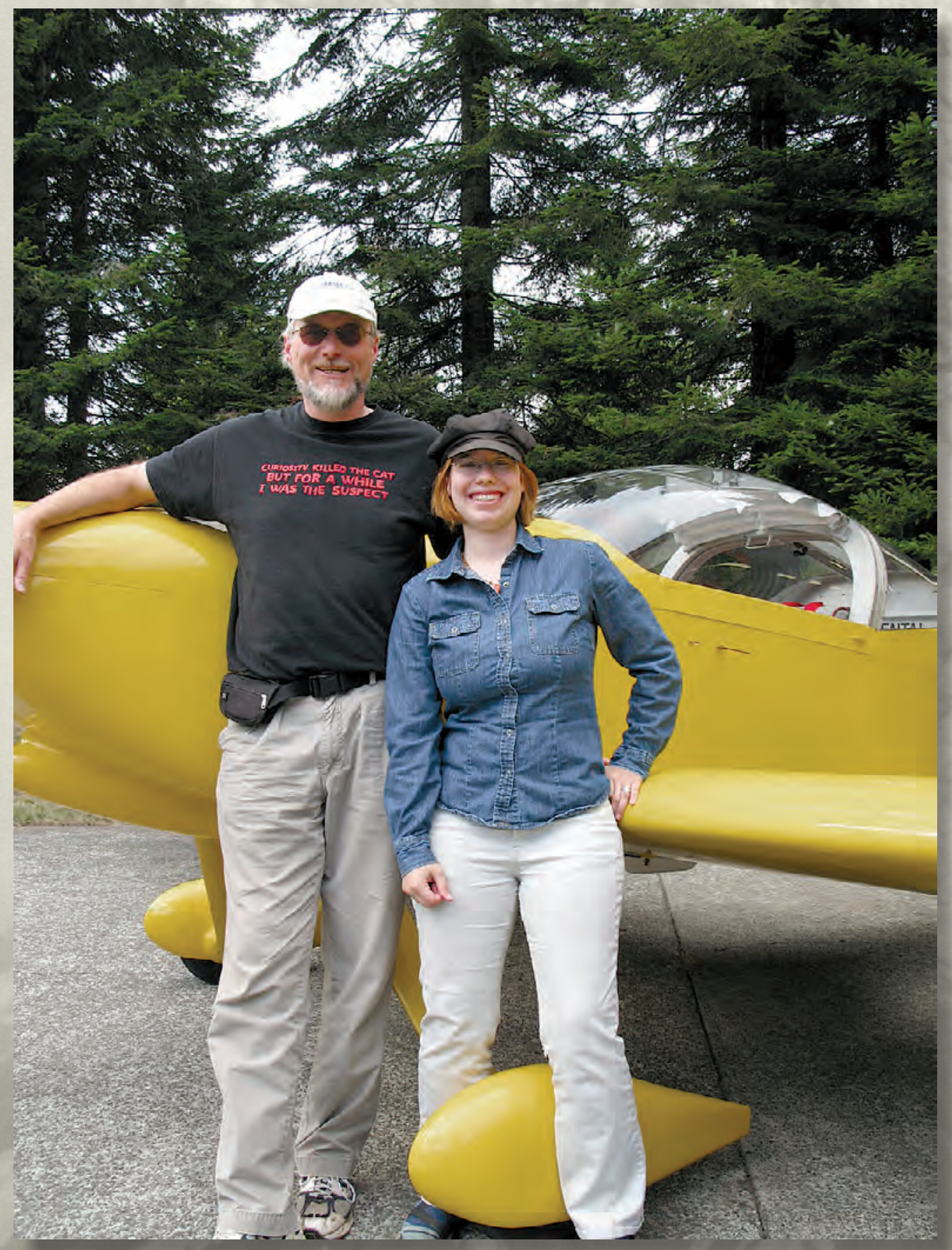

The requirements of participants of the Self-Directed Mentoring Program are as follows:

- Register online to participate in the Self-Directed Mentoring Program

- Attend a three-hour cyber seminar on developing a successful mentoring partnership

- Complete an Action Plan

\begin{abstract}
"Mentoring is one of the ultimate acts of servant leadership. Over the years, I have been blessed with some wonderful mentors. I am thankful for these powerful role models in my life. They gifted me with support, encouragement, insights, wisdom, high standards and expectations, and honest feedback. I hope to pass the gifts I've been given on to others and I know many folks in the USGS do the same. The USGS Mentoring Program provides a mechanism to facilitate this gift-giving and it builds upon the "organic" mentoring and coaching that is already occurring within the organization. The powerful learning that mentoring facilitates will continue to help the USGS achieve its noble mission - now and in the future."-Dianne Jeffries, Chief of the Office of Organizational and Employee Development
\end{abstract}

Mentor and mentoree prepare to fly over Mount St. Helens in the Cascade Range of Washington. The lead scientist and his mentoree were repeating an aerial survey from 2001 to help them determine how the hydrological structure of the volcano had changed in recent years. They spent 2 weeks gathering data on Mount St. Helens. Photograph submitted by Alicia Hotovec, U.S. Geological Survey. 


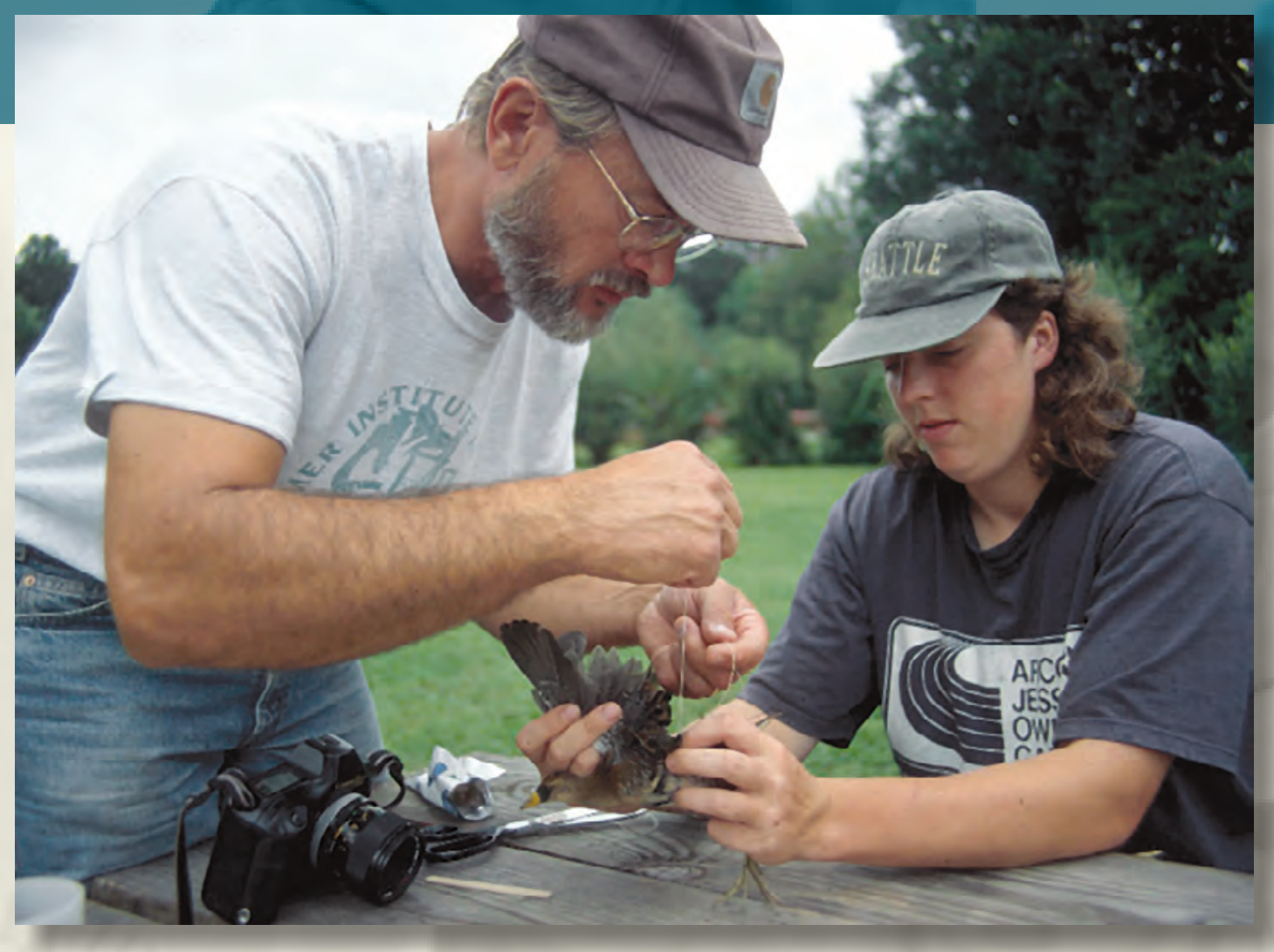

Mentor ties a 2-gram radio transmitter to a sora rail during field studies in the wild rice marshes of the Patuxent River, in Maryland, as mentoree assists. Photograph by Michael Haramis, U.S. Geological Survey.

\section{Science Center Mentoring}

Upon request, the Mentoring Program also offers a Science Center Approach to mentoring that trains employees within a Center how to effectively and intentionally establish successful mentoring partnerships.

The requirements of participants of the Science Center Mentoring Program include the following:

- Science Center employees attend a one-day workshop on developing a successful mentoring partnership

- Science Center Senior Staff work with Mentoring staff to determine goals and objectives for the Science Center Mentoring Program

- Science Center commitment to fostering a mentoring culture

\section{Future Mentoring Programs}

Additional mentoring opportunities under development include a program focused on mentoring for new supervisors, a program for employees with greater than five years of service who are in a career transition, and a program that pairs people across agencies.

"In short, it was an incredibly educational, eye-opening and inspiring experience." —— USGS Mentoree
"The program provides an opportunity for partners to learn from each other and enrich each other's lives and careers with the intent of increased job performance." - USGS Mentor

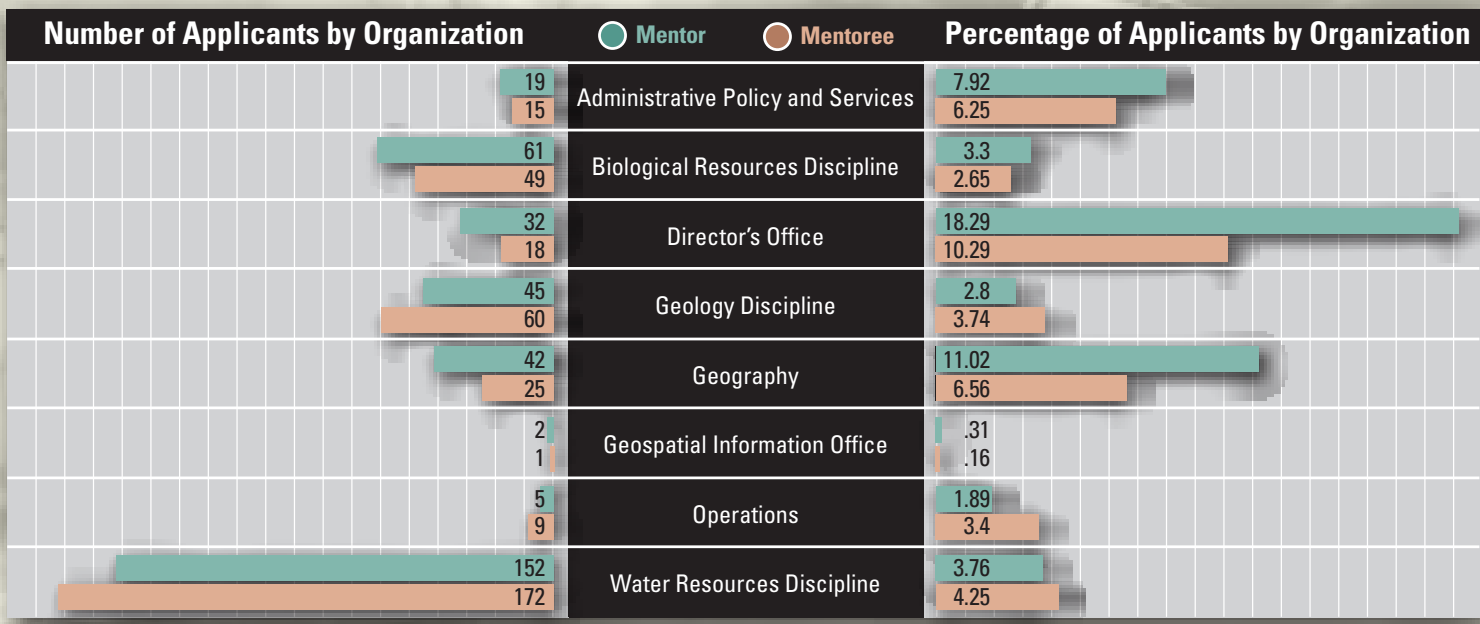

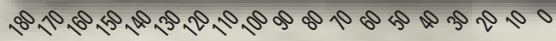
NUMBER OF APPLICANTS 


\section{Total Number of Applicants by Fiscal Year, 2002-2007}

\section{Get a Mentor}

USGS employees who are permanent, SCEP, TERM, or STEP appointments with five years or less of USGS service are eligible to apply for a mentor under the One-Year Guided component of the Mentoring Program. Supervisory approval is required to apply.

Selected applicants will be paired with a qualified USGS mentor. Partners must then participate in a mandatory mentor-shadowing event in which mentorees travel to the duty station of the mentor. Funding for the mentoree's travel is paid for by the USGS, Office of Organizational and Employee Development. Mentoree applications for the OneYear Guided partnerships are accepted on-line at http://geology. usgs.gov/usgs/mentoring.htm.

\section{Be a Mentor}

Employees with greater than five years of USGS service who are willing to mentor other employees are invited to access the USGS Mentoring website and apply to be a mentor.

Both components of the USGS Mentoring

Program, the One-Year Guided component for newer USGS employees and the Self-Directed, which is open to all USGS employees, are premised on a personal decision to voluntarily mentor. It is an extraordinary gift to guide, coach, and to act as a sounding board and confidante for a mentoree. Mentoring also provides the vehicle for sharing professional and technical experience, as well as insights mentors have gained throughout their career. Mentoring can also expand participant's networks across the Bureau, build enduring relationships, and allow mentors to leave a legacy. Consider the mentors who have influenced you. Based on the many successes USGS mentoring partners have already reported, take a calculated risk and apply to be a mentor for either the One-Year Guided component or the Self-Directed component, or both. Mentor applications for the One-Year Guided and Self-Directed partnerships are accepted on-line at http://geology.usgs.gov/usgs/ mentoring.htm. Supervisory approval is required to apply.

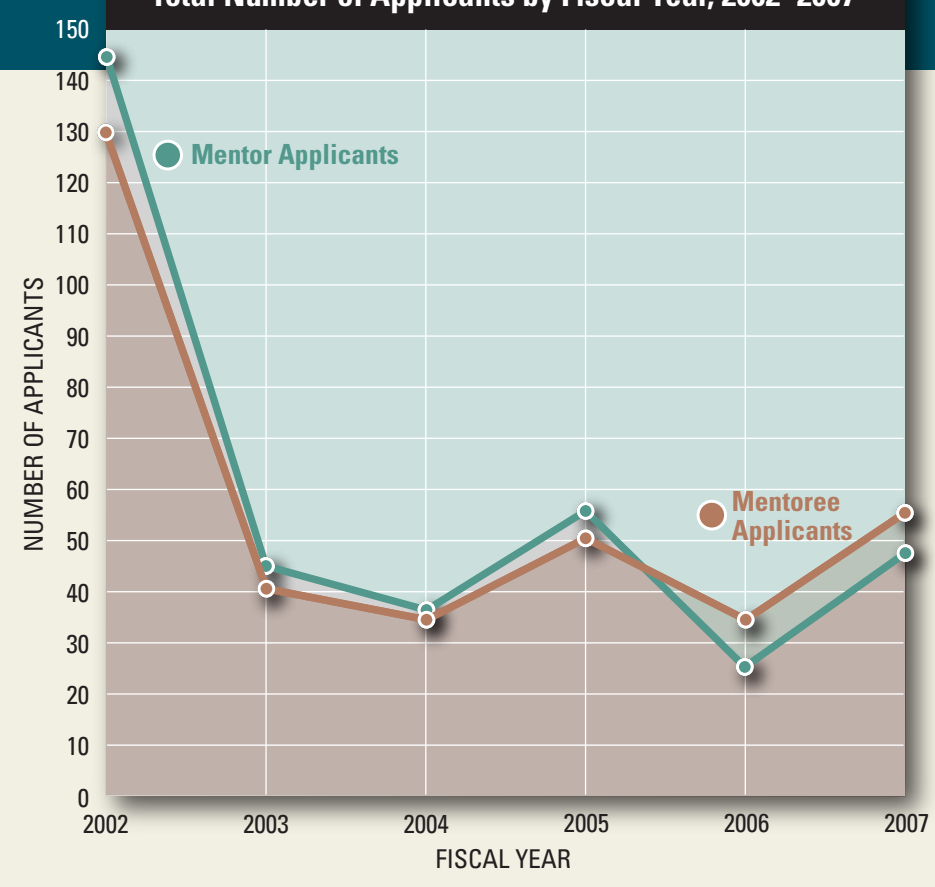

Contacts

If you have any questions regarding the USGS Mentoring Program, or how mentoring can work for you, please contact:

Kim Miller (304) 347-5130 ext. 227

or

Stacey Clarke (303) 445-4674

You can also visit the USGS Mentoring Program website at http://training.usgs.gov and click on

Mentoring Program for more information.

Also check out the online course "Introduction to Mentoring” at URL http://oedbreeze.cr.usgs.gov/ mentoringintro/ to discover what the program is about and how it can help you.

\section{Develop a powerful partnership- Join the USGS Mentoring Program today!}

